\title{
ANALISIS STUDI KELAYAKAN USAHA PENDIRIAN HOME INDUSTRY (STUDI KASUS PADA HOME INDUSTRI "OLLANDA BROWNIES" PANAM PEKANBARU)
}

\author{
Siti Syahsudarmi \\ Sekolah Tinggi Ilmu Ekonomi Riau \\ E-mail: sitisyahsudarmi@gmail.com
}

\begin{abstract}
Brownis home industry "ollanda" is a new bussines that was founded with is own capital, which is equel to $\mathrm{Rp} 28.028 .000$. The produck produced in the form of brownis with various flavors. This study aims to determine the level of investment of a home industry brownis "ollanda" which is lacated Jl. HR. Soebrantas Panam No. 73D, Tuah Karya, kec. Tampan, Pekanbaru City, Riau 28291. This research was conducted in February 2020 with data collection techniques in the form of observation, interviews and dokumentotion. The methods used are market and marketing aspect, engineering aspect and production aspect . organizational and management aspect as well as financial aspect with investment feasibility calculation in the form of payback period(PP), Net Present Value (NPV), Internal Rate of Return (IRR), and Profitability Index( PI). Market and marketing analysis shows that the prospect of the "ollanda" brownis home industry is quite good, seen from the increasing number of requests every year. Technical analysis of production show that the lacation of the home industry is close to settlements making it easier to recruit workers. Analisis of organizational and management personal show that bussines oners have carried out management functions well.
\end{abstract}

Keywords: payback period, Net Present Value, Internal Rate Of Return, Dan Profitability Index

\section{A. PENDAHULUAN}

Brownis adalah kue khas Amerika yang pertama kali dikenal pada tahun 1897 , yang bertekstur lembut, padat serta berwarna coklat kehitaman. Nama brownis sendiri diambil karena dominannya warna cokelat pekat dari cake tersebut, dan juga menggunakan berbagai macam jenis coklat.

Brownis merupakan salah satu cake yang memiliki banyak penggemar mulai dari anakanak sampai orang dewasa. Seiring berkembangnya zaman banyak sekali brownis dengan aneka rasa dan kreasi yang variatif, di Indonesia sendiri yang pertama kali populer adalah brownis dengan cara dipanggang namun beberapa tahun belakangan muncul brownis jenis baru yaitu brownis yang dimasak dengan cara dikukus.

Di kota pekanbaru masyarakat terinspirasi dan berinovasi dengan mendirikan home industry yang bergerak dibidang pangan salah satunya yaitu home industry "ollanda brownies". Usaha ini mempunyai konsep yang berbeda yaitu dengan menghasilkan broduk berupa brownis dalam berbagai bentuk yang disajikan secara istimewa yang mempunyai ukuran $18 \mathrm{~cm}$ dan $22 \mathrm{~cm}$ semakin meningkat dan dapat dilihat dari pesanan konsumen yang disajikan di tabel berikut :
Tabel 1. Data permintaan produk "ollanda brownies"

\begin{tabular}{|c|c|c|c|c|}
\hline \multirow[b]{2}{*}{ No } & \multirow[b]{2}{*}{ Tahun } & \multirow[b]{2}{*}{ Bulan } & \multicolumn{2}{|c|}{ Permintaan (barang) } \\
\hline & & & Ukuran 18 & Ukuran 22 \\
\hline 1 & \multirow{7}{*}{2018} & Juni & 277 & 315 \\
\hline 2 & & Juli & 325 & 217 \\
\hline 3 & & Agustus & 219 & 203 \\
\hline 4 & & September & 288 & 225 \\
\hline 5 & & Oktober & 297 & 201 \\
\hline 6 & & November & 315 & 205 \\
\hline 7 & & Desember & 355 & 225 \\
\hline 8 & 2019 & Januari & 135 & 115 \\
\hline
\end{tabular}

Sumber: "ollanda brownies" (data diolah)

Jumlah produksi brownis ukuran 18 dan 22 sesuai dengan banyaknya jumlah permintaaan konsumen, hal tersebut dikarenakan home industry brownis "ollanda" sesuai dengan banyaknya permintaan untuk mengurangi resiko kerugian. Home industry "ollanda brownies" dalam usahanya masih terus menerus melakukan inovasi dan pengembangan mengingat usaha ini masih dalam tahap perintisan pendirian home industry brownies ini diharapkan menarik para konsumen sehingga mampu meningkatkan penghasilan dan laba usaha dengan produk yang lebih bervariasi. rencana usaha tersebut memerlukan adanya analisis studi kelayakan untuk menilai apakah usulan usaha tersebut diterima atau ditolak. Berdasarkan latar belakang, peneliti tertarik untuk melakukan penelitian dengan judul analisis studi kelayakan usaha 
pendirian home industry (Studi Kasus Pada Home Industri "ollanda brownies" Panam Pekanbaru).

\section{TINJAUAN PUSTAKA INDUSTRI}

Menurut UU No.5 tahun 1984 tentang penindustrian adalah kegiatan ekonomi yang mengolah bahan mentah, bahan baku, barang setengah jadi, dan/atau barang jadi menjadi barang dengan nilai yang lebih tinggi untuk penggunaannya, termasuk kegiatan rancang bangun dan perekayasaan industri. (Pujoalwanto 2014;214)

\section{Tujuan Kegiatan Industri}

Tujuan kegiatan industri adalah:

1. Memperluas lapangan kerja guna menyerap tenaga kerja

2. Meningkatkan pertumbuhan ekonomi nasional

3. Menghasilkan barng-barang yang diperlukan oleh masyarakat terutama bahan pangan, sandang dan papan

4. Menghasilkan devisa dengan cara mengekspor hasil industri atau menghemat devisa dengan cara membatasi impor.

\section{Home Industri}

Menurut kimbal (2015) pengertian industri rumah tangga disebut pula sebagai suatu kegiatan keluarga yaitu sebagai unitunit konsumtif dan ptoduktif yang terdiri dari paling sedikit dua anggota rumah tangga yang sama, sama-sama menanggung pekerjaan, makanan dan tempat berlindung.

\section{Kriteria Home Industry}

Home industri merupakan rumah usaha produk barang atau juga perusahaan kecil, dikatakan usaha kecil karena jenis kegiatan ekonomi ini dipusatkan di rumah. Dijelaskan didalam UU No. 9 Tahun 1995 bahwa usaha kecil adalah usaha dengan kekayaan bersih paling banyak Rp 200 juta (tidak termasuk tanah dana bangunan tempat usaha) dengan hasil penjualan tahunan paling banyak Rp 1.000.000.000.

Kriteria lain dalam UU No. 9 Tahun 1995 adalah : milik WNI, berdiri sendiri, berafiliasi langsung atau tidak langsung dengan usaha menengah atau besar dan berbentuk badan hukum maupun tidak. Home industri juga dapat berarti industri rumah tangga, karena temasuk dalam kategori usaha kecil yang dikelola keluaga.

\section{Manfaat Home Industry}

Adapun beberapa manfaat adanya homr industri adalah:

1. Memberikan lapangan pekerjaan pada penduduk umumnya tidak bekerja secara utuh.

2. Memberikan tambahan pendapatan tidak saja bagi pekerja atau kepentingan keluarga, tetapi juga anggota anggota keluarga lain.

3. Mampu memproduksi barng-barang keperluan penduduk setempat dan daerah sekitarya secra lebih efisien dan lebih murah dibanding industri besar.

Selain itu, home industri juga mempunyai kedudukan yang penting dalam sektor perekonomian yaitu memberi manfaat dari segi sosial yang sangat berperan aktif dalam perekonomian.

Berikut beberapa manfaat lain home industri bagi perekonomian:

1. Menciptakan peluang usaha yang luas namun dengan pembiayaan yang relatif murah

2. Mengambil peranan dalam peningkatan dna mobilisasi tabungan domestik

3. Mempunyai kedudukan komplementer terhadap industri besar dan sedang

4. Mendorong munculnya kewirausahaan domestik sekaligus menghemat sumber daya negara

5. Menggunakan teknologi padat karya, sehingga dapat menciptakan lebih banyak kesempatan kerja dibandingkan yang disediakan oleh perusahaan berskala besar

6. Mendorong proses desentralisasi inter regional dan intra regional, karena usaha kecil home industri dapat berlokasi dikota-kota kecil dan pedesaan.

\section{Studi Kelayakan Bisnis}

Studi kelayakan bisnis merupakan penelitian terhadap rencana bisnis yang tidak hanya menganalisis layak atau

$$
\text { P.ISSN: 1410-7988 E.ISSN: 2614-123X }
$$


tidaknya bisnis dibangun, tetapi juga saat dioperasionalkan secara rutin dalam rangka pencapaian keuntungan yang maksimal untuk waktu yagn tidak ditentukan. Sunyoto (2014).

\section{Aspek-aspek Studi Kelayakan Bisnis}

Menurut suliyanto (2010), terdapat beberapa aspek yang perlu diperhatikan dalam studi kelayakan bisnis, yaitu sebagai berikut:

1. Aspek hukum, aspek yang menganalisis kemampuan pelaku bisnis dalam memenuhi ketentuan hukum dan perizinan yang diperlukan untuk menjalankan bisnis diwilayah tertentu.

2. Aspek lingkungan, aspek lingkungan menganalisis kesesuaian lingkungan sekitar (baik lingkungan operasional, lingkungan dekat, dan lingkungan jauh) dengan ide bisnis yang akan dijalankan. Dalam aspek ini dampak bisnis bagi lingkungan juga dianalisis.

3. Aspek pasar dan pemasaran, aspek pasar menganalisis potensi pasar, intensitas persaingan, market share yang dapat dicapai, serta menganalisis strategi pemasaran yang dapat digunakan untuk mencapai market share yang diharapkan.

4. Aspek teknis dan teknologi, aspek teknis menganalisis kesiapan teknis dan ketersedaan teknologi yang dibutuhkan untuk menjalankan bisnis.

5. Aspek manajemen dan sumber daya manusia, aspek manajemen dan sumber daya manusia manganalisis tahap-tahap pelaksanaan bisnis dan kesiapan tenaga kerja, baik tenaga kerja kasar maupun tenaga kerja terampil yang diperlukan untuk menjalankan bisnis.

6. Aspek keuangan, aspek keuangan menganalisis besarnya biaya investasi dan modal kerja serta tingkat pengembalian investasi dari bisnis yang akan dijalankan.

\section{KRITERIA PENILAIAN INVESTASI}

Menurut Umar (2007;197-201) studi kelayakan terhadap aspek keuangan perlu menganalisis bagaimana perkiraan aliran kas akan terjadi. Pada umumnya ada empat kriteria yang biasa dipertimbangkan untuk dipakai dalam penilaian aliran kas dari suatu

Eko dan Bisnis (Riau Economics and Business Reviewe) Volume 11, Nomor 3, 27 September 2020 investasi, yaitu payback period, Net present value, Internal rate of return,dan profitability Index.

1. Payback period

Menurut Umar $(2007 ; 197)$ payback period adalah suatu periode lyang diperlukan untuk menutup kembali pengeluaran investasi (nitial cash invesment) dengan menggunakan aliran kas, dengan kata lain payback period merupakan ratio antara inital cash invesment dengan cash inflow nya yang hasilnya merupakan satuan waktu .selanjutnya nilai rasio ini dibandingkan dengan maksimum payback per yang diterima.

Payback period $=\frac{\text { nilai investasi }}{\text { kasmasuk besih }} \times 12$ bulan

Kriteria penilaian :

a. Jika payback period lebih pendek waktunya dari maksimum payback period nya maka usulan investasi dapat diterima.

b. Jika payback period lebih panjang dari waktunya dari maksimum payback period nya maka usulan investasi tidak dapat diterima.

Apabila aliran kas suatu nvestasi tidak sama besarnya dari tahun ketahun, dengan sendirinya perhitungan diatas tidak memungkinkan. Oleh karena itu kita peerlu menghitung aliran kas dari tahun ke tahun, sehingga keseluruhan investasi dapat diperoleh kembali.

Kelemahan dari teknik perhitungan payback period adalah:

a. Tidak memperhitungkan nilai waktu uang dan

b. Mengabaikan arus kas setelah payback period

Untuk mengatasi kelemahan karena mengabaikan nilai waktu uang metode perhitungan ini dicoba diperbaiki dengan mem present calue kan arus kas dan dihitung periode paybacknya. Cara ini disebut sebagai discounted payback period.

2. Net Present Value(NPV)

Menurut umar $(2007 ; 200)$ NPV yaitu selisih antara present value dari

P.ISSN: 1410-7988 E.ISSN: 2614-123X 
investasi dengan nilai sekarang dari penerimaan penerimaan kas bersih (aliran kas operasional maupun aliran kas terminal) dimasa yang akan datang. Untuk menghitung nilai sekarang perlu ditentukan tingkat bunga yagn relevan.

$$
\mathrm{NPV}=\sum_{t=t}^{n} \frac{c F t}{1+k t}-10
$$

$\mathrm{CFt}=$ aliran kas pertahun pada periode $\mathrm{t}$

$10=$ investasi awal pada tahun 0

$\mathrm{K}=$ suku bunga (dicount rate)

Kriteria penilaian;

a. Jika NPV>0, maka usulan investasi diterima

b. Jika NPV $<0$, maka usulan proyek ditolak

c. Jika NPV=0, nilai perusahana tetap walau usulan proyek diterima ataupun ditolak

Kelebihan:

a. Secara konseptual adalah yang terbaik dibandingkan dengan payback

b. Tidak menghasilkan aliran kas selama periode proyek

c. Memperhitungkan nilai waktu uang

d. Mudah penerapannya dibandingkan dengan IRR

e. Mengutamakan aliran kas lebih awal

Kelemahan:

a. Memerlukan perhitungan cost of capital sebagai discount rate

b. Lebih sulit penerapannya dibandingkan payback, sehingga sangat sulit digunakan oleh tingkat bawah organisasi, apabila tanpa diadakan pelatihan yang memadai

c. Tanpa adanya perubahan ke aliran kas tahun yang sama, NPV akan menghasilkan perbandingan yang menyimpang terhadap perbandingan antara proyek-proyek yang berukuran tidak sama dan mempunyai unsur ekonomis yagnn tidak sama.

3. Internal Rate of Return

Menurut Umar ( 2007: 198) metode ini digunakan untuk mencari tingkat bunga yagn menyamakan nilai sekarang dari arus kas yang diharapkan dimasa datang, atau penerimaan kas, dengan pengeluaran investasi awal. Rumus yang digunakan sebagai berikut ;

$$
I o=\sum_{t=1}^{n} \frac{C F t}{(1+I R R) t}
$$

$\mathrm{t}=$ tahun $\mathrm{ke}$

$\mathrm{n}=$ jumlah tahun

$\mathrm{Io}=$ nilai investasi awal

$\mathrm{CF}=$ arus kas bersih

$\mathrm{IRR}=$ tingkat bunga yang dicari harganya

Kriteria penilaian:

Jika IRR yang didapat ternyata lebih besar dari rate of return yang ditentukan maka investasi dapat diterima.

Rumus IRR untuk interpolasi adalah:

$\mathrm{IRR}=(\mathrm{P} 1-\mathrm{C} 1)+\frac{(P 2-P 1)}{(P 2-P 1)}$

$\mathrm{P} 1=$ tingkat bunga ke 1

$\mathrm{P} 2=$ tingkat bunga ke 2

$\mathrm{C} 1=$ net present value dari hasil internal rate ke 1

$\mathrm{C} 2=$ net present value dari hasil internal rate ke 2

Kritera diterima atau ditolaknya suatu usulan rencana investasi dinyatakan:

a. IRR> required rate of return diterima

b. $\quad$ IRR $<$ requred rate of return ditolak

4. Profitability Index (PI)

Menurut Umar (2007; 201) pemakaian

PI ini caranya adalah dengan menghitung melalui perbandingan antara nilai sekarang dari rencana penerimaan penerimaan kas bersih dimasa yang akan datang dengan nilai sekarang dari investasi yang telah dilaksanakan. Jadi, PI dapat dihitung dengan membandingkan antara PV kas masuk dengan PV kas keluar.

$$
\mathrm{PI}=\frac{\text { PV kas masuk }}{\text { PV kas kelwar }}
$$

Kriteria penilaian;

a. Jika PI>1, maka usulan proyek dikatakan menguntungkan.

b. Jika $\mathrm{PI}<1$, maka usulan proyek tidak menguntungkan

Kriteria ini erat hubungannya dengan kriteria NPV, dimana jika NPV suatu proyek dikatakan layak maka menurut PI juga layak karena kedunya menggunakan variabel yang sama. 


\section{METODE}

\section{Jenis Penelitian}

Jenis penelitian ini adalah penelitian deskriptif. Penelitian deskriptif dalam penelitian ini berisi tentang gambaran mengenai lokasi perusahaan dan kelayakan usaha ditinjau dari berbagai aspek-aspek tertentu.

\section{Fokus Penelitian}

lain:

Fokus penelitian ini adalah antara

1. Aspek Pasar dan Pemasaran, meliputi:
a. Permintaan pasar
b. Pesaing
c. Pangsa pasar
d. Strategi dan bauran pemasaran

2. Aspek Teknis dan Produksi, yaitu:
a. Lokasi produksi
b. Bahan baku, bahan tambahan, dan bahan penolong
c. Teknologi yang digunakan
d. Proses produksi

3. Aspek Organisasi dan Manajemen, meliputi:
a. Struktur organisasi
b. Jumlah dan kualifikasi tenaga kerja

4. Aspek Finansial, meliputi:
a. Kebutuhan dana
b. Sumber dana
c. Modal kerja

\section{Lokasi Penelitian}

Lokasi analisis studi kelayakan usaha ini dilakukan pada home industry "ollanda brownies" " yang beralamat di lingkungan J1. HR. Soebrantas Panam Kelurahan No. 73 D, Tuah Karya, Kec. Tampan, Kota Pekanbaru, Riau 28291.

\section{Jenis dan Sumber Data}

Jenis data terbagi menjadi dua, yaitu data premier dan data sekunder. Sumber data primer dalam penelitian ini diperoleh langsung melalui observasi dan wawancara dengan berbagai pihak berupa informasi terkait dengan kondisi perusahaan,meliputi gambaran umum perusahaan, produk-produk yang dihasilkan, jenis peralatan yang digunakan, serta proses produksi. Sumber data sekunder penelitian ini diperoleh dari data perusahaan berupa data permintaan dan data yang diperoleh dari data literatur.

\section{Pengumpulan Data}

Pengumpulan data dalam penelitian ini dilakukan dengan beberapa cara, diantaranya adalah :
1. Observasi
2. Wawancara
3. Dokumentasi

\section{Instrumen penelitian}

Penelitian ini menggunakan instrument penelitian berupa

1. Pedoman observasi

2. Pedoman wawancara

3. Pedoman dokumentasi

\section{Metode analisis}

Metode analisis yang digunakan dalam penelitian ini terdiri dari beberapa aspek, yaitu:

1. Aspek Pasar dan Pemasaran, meliputi:
a. Menganalisis permintaan pasar
b. Menganalisis pesaing
c. Menganalisis pangsa pasar
d. Menganalisis strategi dan bauran pemasaran

2. Aspek Teknis dan Produksi, meliputi:
a. Menganalisis lokasi produksi
b. Menganalisis bahan baku, bahan tambahan, dan bahan penolong

c. Menganalisis teknologi yang digunakan

d. Menganalisis proses produksi

3. Aspek Organisasi dan Manajemen, meliputi:

a. Menganalisis struktur organisasi

b. Menganalisis jumlah dan kualifikasi tenaga kerja

4. Aspek Finansial, meliputi:
a. Menganalisis kebutuhan dana
b. Menganalisis sumber dana
c. Menganalisis modal kerja
d. Menghitung proyeksi rugi/laba
e. Menghitung proyeksi arus kas masuk (cash inflow) 
f. Menganalisis kelayakan berdasarkan kriteria penilaian investasi yang terdiri dari:
1) Payback Period (PP)
2) Net Present Value (NPV)
3) Internal Rate of Return (IRR)

4) Profitability Index (PI)

\section{HASIL}

Analisis Kelayakan terhadap Aspek Pasar dan Pemasaran

1. Permintaan Pasar

Permintaan produk "ollanda brownies" baik ukuran 18 ataupun 22 mengalami naik turun jumlah pesanan tiap bulan. Proyeksi permintaan ollanda baik ukuran 18 maupun 22 dapat dihitung dengan metode trend linier, dengan hasil sebagai berikut:

Tabel 2. Proyeksi permintaan produk "ollanda brownies"

\begin{tabular}{|l|l|l|}
\hline \multirow{2}{*}{ Tahun } & \multicolumn{2}{|l|}{ Permintaan $(\mathrm{kg})$} \\
\cline { 2 - 3 } & Ukuran 18 & Ukuran 22 \\
\hline 2019 & 2.951 & 2.591 \\
\hline 2020 & 3.113 & 3.815 \\
\hline 2021 & 3.205 & 4.881 \\
\hline 2022 & 2.957 & 2.717 \\
\hline 2023 & 4.584 & 3.768 \\
\hline
\end{tabular}

Sumber : Data olahan, 2019

2. Pesaing

Pesaing bisnis "ollanda brownies" di kota pekanbaru panam yaitu Amanda brownies dan Chi'a brownies. Kedua pesaing tersebut sama-sama memproduksi brownis dan cake dalam berbagai variasi bentuk dan rasa. Amanda brownis memproduksi brownis kukus yang banyak diminati masyarakat bahkan penjualannya laris manis tiap tahun begitu juga dengan chi'a brownies. kisaran harga untuk brownies Amanda dari Rp. 43.000-65.000 sedangkan harga dari chi'a brownis yaitu dar Rp. 4.000 - 44.000.

3. Pangsa pasar

Pangsa pasar "ollanda brownies" cukup luas dengan konsumen dari semua kalangan karena harga yang ditetapkan terjangkau. "ollanda brownies" sudah tersebar dibeberapa daerah dipekanbaru

Eko dan Bisnis (Riau Economics and Business Reviewe) Volume 11, Nomor 3, 27 September 2020 diantaranya panam, simpang tiga, harapan raya, rumbai dan marpoyan.

4. Bauran pemasaran

1) Produk (product)

Home industry "ollanda brownies" mengeluarkan beberapa jenis brownis dengan ukuran $18 \mathrm{~cm}$ dan $22 \mathrm{~cm}$. "ollanda brownies" juga mempunyai macam-macam brownis seperti original, black forest ,kukus dan brownis bakar.

2) Harga (price)

Penetapan harga pada produk ditentukan pada hitungan tertentu secara dan konsisten serta berdasarkan setiap pengeluaran dalam membeli bahan baku dan proses pengerjaan produksi. Harga yang ditetapkan untuk setiap produk bermacam-macam pada ukuran 18 harganya Rp. 85.000 per pcs unruk ukuran 22 harganya Rp. 120.000. untuk berbaga varian rasa.

3) Distribusi (place)

Distribusi produk "ollanda brownies" mudah dan masih sederhana, sehingga tidak mengalami banyak kendala. Rantai distribusi hasil produksi ollanda dari produsen ke konsumen relative pendek.

4) Promosi (promotion)

Home industry "ollanda brownies" melakukan kegiatan promosi melalui media online, jaringan, promosi manual, dari mulut kemulut dan membawa brosur bagi setiap pembelian

Analisis kelayakan terhadap aspek teknis dan produksi

1. Lokasi produksi

Tempat produksi usaha merupakan toko sendiri yang beralamat di jalan kaharuddin Nasution nomor 88 kelurahan simpang tiga kecamatan bukit raya, pekanbaru riau.

2. Bahan baku, bahan tambahan, dan bahan penolong

Bahan baku yang diperlukan dalam proses produksi yaitu tepung, gula,

P.ISSN: 1410-7988 E.ISSN: 2614-123X 
cokelat, telur, dan margarine. Bahan tambahan berupa susu, keju, vanilla, baking powder, soda, tbm, sp.

Bahan penolong digunakan dalam proses pengemasan produk antara lain : kertas roti, stiker kemasan serta kotak. Harga bahan baku ukuran 18 berkisar 30.000 dan pada ukuran 22 harga bahan baku berkisar 45.000 per kotak.

3. Peralatan produksi

Peralatan produksi berupa oven, Loyang, baskom adonan, mixer, gelas ukuran, parutan, kulkas, timbangan, spatula, dan alat kukus. Semua peralatan untuk produksi dalam keadaan bagus dan bersih.

4. Proses produksi

Proses produksi yang dilakukan masih sederhana dan secara manual mengingat usaha ini belum mempunyai alat teknologi yang mendukung, sehingga masih mengandalkan tenaga manusia. Produksi dipengaruhi oleh jumlah permintaan pasar karena home industry ini masih dalam tahap perintisan. Tahap proses produksi pada home industry "ollanda brownies" digambarkan sebagai berikut :

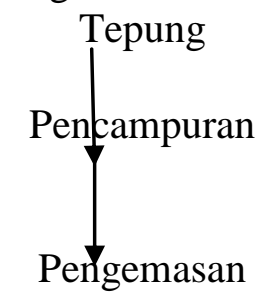

Gambar 1. Alur Proses Produksi

Sumber : Data olahan, 2019

\section{Analisis kelayakan terhadap aspek organisasi dan manajemen}

1. Struktur organisasi

Struktur organisasi home industry "ollanda brownies" disusun secara sederhana yaitu pemilik dan pemimpin usaha berada diposisi atas. terdapat dua devisi dalam struktur organisasi yaitu devisi produksi dan devisi penjualan.

Pelaksana dimana masing-masing tenaga kerja melakukan tugas (jobdesc) yang telah ditentukan. Tenaga kerja masih sedikit, antara pemilik usaha dengan tenaga kerja memiliki hubungan sangat dekat, dengan tingkat spesialisasi yang belum tinggi.

2. Jumlah tenaga kerja

Tenaga kerja home industry "ollanda brownies" berjumlah 14 orang dengan kualifikasi pendidikan SMA. Tenaga kerja yang terlibat dalam usaha "brownis ollanda" terbagi menjad2 dua devisi yaitu devisi produksi 9 orang dan devisi penjualan 5 orang.

Kegiatan usaha "ollanda brownies" masih sederhana sehingga tidak membutuhkan pekerja yang terlalu banyak, akan tetapi dengan jumlah tenaga kerja yang sedikit mampu menghasilkan output yang maksimal.

3. Kualifikasi tenaga kerja

Tenaga kerja yang ada secara umum bukan merupakan kualifikasi tenaga kerja tetap, akan tetapi lebih kepada tenaga kerja lepas atau join kerja dengan perhitungan keuntungan tertentu.

4. Sistem pengupahan dan pelatihan

Pengupahan tenaga kerja sistemnya bermacam-macam, menggunakan sistem bonus per unit dari hasil produksi dan untuk devisi penjualan menggunakan royalty. Semua tenaga kerja mendapatkan proses training (pelatihan) selama bekerja di "ollanda brownies" . Pelatihan oleh pemilik usaha diadakan setiap ada jenis produk yang baru, sehingga tenaga kerja dapat langsung mempelajari proses produksi dan proses penjualan yang akan diterapkan. Proses training bersifat non formal dan bertujuan agar kualitas setiap produk yang dihasilkan tetap terjaga.

\section{Analisis kelayakan terhadap aspek financial kebutuhan dana}

Dana yang dibutuhkan pada permulaan pendirian home industry brownis ollanda terdiri dari 2,yaitu untuk aktiva tetap dan untuk modal kerja. 
Tabel 3. Rincian kebutuhan dana home industry " Brownis Ollanda" tahun 2018

\begin{tabular}{|l|l|l|}
\hline Kebutuhan dana & Jumlah \\
\hline aktiva tetap & 15.000 .000 & \\
\hline Oven & 100.000 & \\
\hline Loyang & 850.000 & \\
\hline Etalase & 240.000 & \\
\hline Baskom adonan & 1.300 .000 & \\
\hline Mixer & 350.000 & \\
\hline Timbangan digital & 15.000 & \\
\hline Spatula & 1.100 .000 & \\
\hline Alat kukus & 6.000 & \\
\hline Gelas ukur & 20.000 & \\
\hline Alat parutan & 4.000 .0000 & \\
\hline Kulkas & 20.000 & \\
\hline Pisau/gunting & 25.000 & \\
\hline Ayakan & Rp 100.000 & \\
\hline Kertas roti & Rp 75.000 & \\
\hline Rak pendingin & & \\
\hline Jumlah aktiva tetap & & \\
\hline Modal kerja & 3.400 .000 & \\
\hline Kas & 170.000 & \\
\hline Tepung terigu & 370.000 & \\
\hline Gula pasir & 110.000 & \\
\hline Bahan coklat & 40.000 & \\
\hline Margarine & 45.000 & \\
\hline Telur & 692.000 & \\
\hline bahan lain & & \\
\hline Jumlah modal kerja & & \\
\hline Jumlah kebutuhan dana & \\
\hline
\end{tabular}

Sumber : Data olahan, 2019

\section{Sumber Dana}

Sumber dana yang dibutuhkan home industry "ollanda brownies" berasal dari modal sendiri. Modal yang digunakan untuk mendirikan usaha iini yaitu sebesar $\mathrm{Rp}$ 28.028.000 .

\section{Modal Kerja}

Biaya yang dikeluarkan untuk pengadaan peralatan produksi terdiri dari kas untuk membiayai upah tenaga kerja, tranportasi, serta biaya listrik dan air. Kemudian bahan pembuat brownis yang terdiri dari bahan baku dan bahan tambahan. Bahan lain lain terdiri dari perlengkapan yang digunakan untuk memproduksi brownis. Rincian biaya disajikan dalam tabel berikut ini :

Eko dan Bisnis (Riau Economics and Business Reviewe) Volume 11, Nomor 3, 27 September 2020
Tabel 4. Rincian biaya modal kerja home industry brownis "ollanda" tahun 2018

\begin{tabular}{|l|l|l|}
\hline Jenis & Keterangan & Biaya \\
\hline Kas & Bahan baku & 3.400 .000 \\
\hline Bahan brownis & Bahan tambahan & 625.000 \\
\hline \multirow{5}{*}{ Bahan lain-lain } & Keju & 155.000 \\
\cline { 2 - 3 } & $\begin{array}{l}\text { Sp, tbm, baking } \\
\text { soda, baking } \\
\text { powder }\end{array}$ & 50.000 \\
\cline { 2 - 3 } & Vanilla & 12.000 \\
\cline { 2 - 3 } & Plastik & 40.000 \\
\cline { 2 - 3 } & kotak & 210.000 \\
\cline { 2 - 3 } & stiker & 75.000 \\
\hline Total & & 4.827 .000 \\
\hline
\end{tabular}

Sumber : Data olahan, 2019

\section{Proyeksi pendapatan}

Proyeksi pendapatan home industry untuk produk "ollanda brownies" ukuran 18 disajikan dalam table berikut :

Tabel 5. Proyeksi pendapatan home industry "ollanda brownies" ukuran 18

Proyeksi pendapatan untuk produk "ollanda brownies" ukuran 18 disajikan dalam tabel berikut :

\begin{tabular}{|l|l|l|l|}
\hline Tahun & $\begin{array}{l}\text { Kuantit } \\
\text { as (pcs) }\end{array}$ & $\begin{array}{l}\text { Harga } \\
\text { jual }\end{array}$ & Pendapatan \\
\hline 2018 & 2.951 & 85.000 & 250.835 .000 \\
\hline 2019 & 3.113 & 85.000 & 264.605 .000 \\
\hline 2020 & 3.205 & 85.000 & 272.425 .000 \\
\hline 2021 & 2.957 & 85.000 & 251.345 .000 \\
\hline 2022 & 4.584 & 85.000 & 389.640 .000 \\
\hline 2023 & 5.195 & 85.000 & 441.575 .000 \\
\hline
\end{tabular}

Sumber : Data olahan, 2019

Sedangkan Proyeksi pendapatan untuk produk "ollanda brownies" ukuran 22 disajikan dalam tabel berikut :

Tabel 6. Proyeksi pendapatan "ollanda brownies" ukuran 22

\begin{tabular}{|l|l|l|l|}
\hline Tahun & $\begin{array}{l}\text { Kuantita } \\
\text { s (pcs) }\end{array}$ & Harga jual & Pendapatan \\
\hline 2018 & 2.591 & 120.000 & 354.120 .000 \\
\hline 2019 & 3.815 & 120.000 & 457.800 .000 \\
\hline 2020 & 4.881 & 120.000 & 585.720 .000 \\
\hline 2021 & 2.717 & 120.000 & 326.040 .000 \\
\hline 2022 & 3.768 & 120.000 & 452.160 .000 \\
\hline 2023 & 3.524 & 120.000 & 422.880 .000 \\
\hline
\end{tabular}

Sumber : Data olahan, 2019

\section{Proyeksi biaya}

Biaya biaya yang dikeluarkan home industry "ollanda brownies" adalah biaya untuk upah tenaga kerja, biaya depresiasi,

\section{P.ISSN: 1410-7988 E.ISSN: 2614-123X}


biaya listrik dan air, serta biaya operasional yang meliputi biaya transportasi.

Perhitungan biaya penyusutan atau biaya despresiasi menggunakan menggunakan metode garis lurus tanpa nilai sisa. Proyeksi biaya operasional yang dikeluarkan home industry "ollanda brownies" untuk lima tahun mendatang disajikan dalam tabel berikut :

Tabel 7. Proyeksi biaya operasional home industry "ollanda brownies"

\begin{tabular}{|l|l|l|}
\hline Tahun & Biaya transportasi & $\begin{array}{l}\text { Biaya } \\
\text { pemasaran }\end{array}$ \\
\hline 2018 & 2.300 .000 & 1.900 .000 \\
\hline 2019 & 3.210 .000 & 2.700 .000 \\
\hline 2020 & 3.540 .000 & 2.900 .000 \\
\hline 2021 & 4.200 .000 & 3.400 .000 \\
\hline 2022 & 5.600 .000 & 4.550 .000 \\
\hline 2023 & 3.920 .000 & 3.100 .000 \\
\hline
\end{tabular}

Sumber : Data olahan, 2019

\section{Cash inflow}

Cash inflow diperoleh dari laba bersih ditambah biaya penyusutan atau depresiasi. Home industry "ollanda brownies" menggunakan $100 \%$ modal sendiri, maka perhitungan Cash Inflow mulai maret 2018 sampai april 2023 adalah sebagai berikut:

Tabel 8. proyek cash inflow home industry "ollanda brownies"

\begin{tabular}{|l|l|l|l|}
\hline Tahun & $\begin{array}{l}\text { Laba } \\
\text { bersih(EAT) }\end{array}$ & Depresiasi & $\begin{array}{l}\text { Cash inflow } \\
\text { (CI) }\end{array}$ \\
\hline 2018 & 413.959 .500 & 4.640 .000 & 418.599 .500 \\
\hline 2019 & 501.664 .500 & 4.640 .000 & 506.304 .500 \\
\hline 2020 & 605.830 .500 & 4.640 .000 & 610.470 .000 \\
\hline 2021 & 369.346 .500 & 4.640 .000 & 373.986 .500 \\
\hline 2022 & 582.120 .000 & 4.640 .000 & 586.760 .000 \\
\hline 2023 & 602.809 .500 & 4.640 .000 & 607.449 .500 \\
\hline
\end{tabular}

Sumber : Data olahan, 2019

\section{Kriteria Penilaian Investasi}

Metode yang digunakan untuk menilai kelayakan investasi yaitu metode konvensional yang terdiri dari payback period (PP), metode Discounted cash flow terdiri dari net present value (NPV), Internal rate of return (IRR), dan profitability index (PI). Ringkasan hasil analisis kelayakan investasi dapat dilihat pada tabel sebagai berikut :

Eko dan Bisnis (Riau Economics and Business Reviewe) Volume 11, Nomor 3, 27 September 2020
Tabel 9. Hasil analisis kelayakan financial home industry "ollanda brownies"

\begin{tabular}{|l|l|l|l|}
\hline No & $\begin{array}{l}\text { Alat } \\
\text { analisis }\end{array}$ & Hasil analisis & Keterangan \\
\hline 1 & PP & $\mathbf{8}$ bulan pas & Layak \\
\hline 2 & NPV & $\mathbf{1 . 9 7 3 . 7 7 6 . 0 3 4}$ & Layak \\
\hline 3 & IRR & $\mathbf{1 8 7 \%}$ & Layak \\
\hline 4 & PI & $\mathbf{9 , 3 2}$ & Layak \\
\hline
\end{tabular}

Sumber : Data olahan, 2019

1) Payback Period (PP)

2) Net Present Value (NPV)

3) Internal Rate of Return (IRR)

4) Profitability Index (PI)

1. $\mathbf{P P}=\frac{\text { INVESTASI AWAL }}{\text { ARUS KAS }} \mathrm{X}$ Tahun $=\frac{336.336 .000}{418.456 .000} X 1$ Tahun $=0,8$ (pengembalian 8 bulan)

2. $\mathbf{I R R}=$

$\frac{\text { CASH FLOW }}{(1+r) i}-$ initial investment

$=\frac{3.103 .570 .000}{(1+0,070) 5}-336.336 .000$

$=\frac{3.103 .570 .000}{1.402}-336.336 .000$

$=2.213 .673 .324-336.336 .000$

$=1.877 .337 .324$

$=187 \%$

3. $\mathbf{P I}=\frac{\text { TOTAL PV KAS BERSIH }}{\text { PVINVESTASI }}$

$=\frac{2.213 .673 .324}{239.897 .290}$

$=9,23$

4. NPV = PV KAS BERSIH - PV INVESTASI

$$
\begin{aligned}
& =\text { 2.213.673.324-239. } 897.290 \\
& =1.973 .776 .034
\end{aligned}
$$

Hasil perhitungan kelayakan investasi yang meliputi PP, NPV, IRR, dan PI menunjukkan bahwa home industry "ollanda brownies" layak untuk dijalankan, karena masing-masing perhitungan memenuhi kriteria investari. Payback period yang dihasilkan yaitu 3 bulan 4 hari, lebih pendek dari umur invetasi yaitu 5 tahun, Nilai NPV sebesar 780.901.417 dimana lebih dari nol, IRR yang diperoleh yaitu $187 \%$ dan lebih besar dari tingkat suku bunga yaitu 7\%, serta hasil perhitungan PI menunjukkan angka 13.087, maka home industry brownis "ollanda" layak dijalankan 


\section{SIMPULAN}

1. Analisis pasar dan pemasaran menunjukkan bahwa prospek home industry "ollanda brownies" cukup baik, hal ini dilihat dari peningkatan jumlah permintaan setiap tahun. Ketersediaan bahan baku dan bahan pembantu yang memadai, dan strategi terkait bauran pemasaran yang cukup bagus.

2. Analisis teknik dan produksi menunjukkan bahwa kondisi tempat serta peralatan produksi tetap bersih dan terjaga kualitasnya, serta memenuhi kapasitas produksi.

3. Analisis organisasi dan manajemen menunjukkan bahwa pemilik usaha telah menjalankan fungsi-fungsi manajemen yang cukup baik dimulai dari perencanaan, pengorganisasian, pengarahan, dan pengendalian walaupun karyawan pada umumnya lulusan SMA/sederajat. Pemilik usaha berupaya untuk menjalin hubungan yang baik dengan karyawan dan membina solidaritas yang tinggi antar karyawan.

4. Analisis financial dengan menggunakan $100 \%$ modal sendiri dikatakan layak berdasarkan hasil perhitungan kelayakan investasi yang meliputi payback period (PP), Net present value(NPV), Internal rate of return (IRR), Dan profitability index (PI), Karena masing masing perhitungan memenuhi criteria investasi, dimana nilai $\mathrm{pp}$ atau janga waktu pengembalian modal kurang dari umur investasi (5 tahun),

\section{Saran}

1. Sebaiknya kegiatan home industry "ollanda brownies" terus dikembangkan karena layak untuk dilaksanakan

2. Meningkatkan promosi penjualan, tidak hanya pada daerah pemasaran yang ada namun juga daerah baru dengan memperluas pangsa pasar mengingat permintaan produk yang tinggi.
3. Perlu adanya kualifikasi tenaga kerja dalam proses rekruitmen atau mulai menerima karyawan lulusan S1.

4. Pemanfaatan lahan produksi perlu ditingkatkan agar dapat memenuhi kapasitas produk brownis yang diminta oleh pasar, serta pengembangan mesin dan peralatan produksi yang lebih memadai atau agar supaya lebih mudah meningkatkan produksi.

Sebaiknya home industry "ollanda brownies"melakukan pinjaman modal dalam hal pengembangan usaha, tidak hanya mengandalkan modal sendiri sehingga terdapat motivasi berwirausaha dan terus melakukan inovasi-inovasi baru

\section{DAFTAR RUJUKAN}

https://chia-brownies. business.site

Kimbal. R.W. (2015). Modal Sosial dan Ekonomi Industri kecil: sebuah studi kualitatif. Yogyakarta, penerbit Depublis.

Pujoalwanto, Basuki. (2014). Perekonomian Indonesia: Tinjauan Historis, Teoritis, dan Empiris. Yogyakarta: Graha Ilmu.

Suliyanto. (2010) . studi kelayakan bisnis pendekatan praktis. Yogyakarta: Andi.

Sunyoto, Danang. (2014). Studi kelayakan Bisnis. Yogyakarta: CAPS (Center of Academic Publishing Service).

Umar, Husein. (2007). Metode Penelitan untuk Skripsi dan Tesis Bisnis, Ed 8 Baru. Jakarta: Penerbit PT Raja Grafindo Persada 